\title{
Pobres no Campo, Ricos na Cidade? Uma Análise Multidimensional da Pobreza ${ }^{1}$
}

\author{
Rodolfo Ferreira Ribeiro da Costa $^{2}$ e Genivalda Cordeiro Costa ${ }^{3}$
}

Resumo: O objetivo deste trabalho é identificar se existe uma relação entre os níveis de pobreza rural e urbano. Para isso, primeiramente foi auferido o patamar de pobreza para ambos os espaços, baseado na definição de pobreza multidimensional, admitindo, portanto, que as carências em saúde, renda, educação e moradia são componentes fundamentais para mensuração das privações. A abordagem utilizada para o indicador de pobreza multidimensional foi a lógica fuzzy, enquanto que a análise de dependência entre os indicadores foi desenvolvida através da função Cópula. Os dados remetem as áreas rurais e urbanas dos 5.565 municípios brasileiros em 2010. Por um lado, verificou-se que aquelas áreas rurais com maiores carências se fazem presentes na região Nordeste, por outro, nos espaços urbanos, a situação mais preocupante é a da região Sudeste. Por fim, a análise de dependência entre os indicadores sugere uma relação negativa, indicando que, quando a pobreza rural se agrava, aquela relacionada à zona urbana torna-se mais branda.

Palavras-chaves: Pobreza multidimensional; Rural; Urbano; Fuzzy; Cópula.

Abstract: The aim of this study is to identify whether there is a relationship between rural and urban poverty levels. For this, it first earned the poverty line for both areas based on the definition of multidimensional poverty, assuming therefore that the deficiencies in health, income, education and housing are fundamental components for measurement of deprivation. The approach to multidimensional poverty indicator was the fuzzy logic, while the dependency analysis between the indicators was developed through the Copula function. The data refer to urban and rural areas of the 5,565 Brazilian municipalities in 2010. On the one hand, it was found that those rural areas in greatest need are present in the Northeast; on the other, in urban areas, the most worrying situation is the Southeast.

1. Data de submissão: 18 de maio de 2015. Data de aceite: 14 de junho de 2016.

2. Universidade do Estado do Rio Grande do Norte. Mossoró/RN, Brasil. E-mail: rodolfofrc@yahoo.com.br

3. Universidade do Estado do Rio Grande do Norte. Mossoró/RN, Brasil. E-mail: genivaldacordeiro@yahoo.com.br 
Finally, the analysis of dependence between indicators suggests a negative correlation, indicating that when rural poverty worsens, that related to urban area becomes milder.

Key-words: Multidimensional poverty; Rural; Urban; Fuzzy; Copula.

DOI - http://dx.doi.org/10.1590/1234-56781806-94790540308

Classificação JEL: R10, C10, I32.

\section{Introdução}

A pobreza é um fenômeno que afeta milhões de pessoas no Brasil e no mundo, tendo um conjunto distinto de fatores que explicam a existência e o aprofundamento da mesma, tanto em áreas urbanas, quanto rurais. No entanto, diversos estudos se dedicaram a explicar a pobreza como um fenômeno unidimensional, ou seja, apenas na dimensão monetária, como sendo resultante apenas da escassez de recursos monetários, decorrentes da má distribuição de renda. Porém, estudos desenvolvidos nas duas últimas décadas têm demonstrado que a pobreza é um fenômeno de natureza multidimensional e, consequentemente, esforços têm sido realizados no sentido de construir indicadores de pobreza que contemplem as diversas formas de privações.

A relevância dada aos estudos sobre pobreza cujas análises são multidimensionais deve-se, principalmente, ao fato de abordarem indicadores que contemplam diferentes formas de privações. Índices de pobreza que extrapolam a natureza monetária são formalmente direcionados às óticas da saúde, educação, habitação, água, terra etc. auferindo, portanto, o patamar de um conjunto distinto de carências, como visto em Lemmi (2005), ao estudar a pobreza na Itália nos anos de 1990, e em Carvalho, Kerstenetzky e Vecchio (2007), ao analisar o caso da pobreza nas regiões metropolitanas do Sudeste brasileiro em 2000.
Neste sentido, podem ser destacar duas questões praticamente inexploradas. A primeira diz respeito à relação de endogeneidade existente entre as diferentes formas de privações pelas quais passam uma sociedade. Trabalhos como Angell (1993), Hurowitz (1993), Smith (1999), Soares (2006), Case e Deaton (2005) e Santos; Jacinto; Tejada (2012) tratam os efeitos da pobreza monetária, Psacharopoulos e Patrinos (2002), Tilak (2005), Wilson (2001) e Schultz (1995) discutem os efeitos da carência em educação e, ainda, Buddelmeyer e Cai (2009), Fuchs (2004), Glewwe e Jacoby (1994), Sanchés e Sbrana (2010) e Shashidhar, Rao e Hedge (2009) evidenciam os efeitos da precariedade da saúde; contudo, raros são os esforços em avaliar as inter-relações entre tais dimensões de forma conjunta.

A segunda remete-se à avaliação da relação destes indicadores multidimensionais de pobreza em diferentes espaços de forma que se possa inferir sobre o modo como a situação de pobreza reage à implementação de políticas, admitindo que os agentes tratados encontram-se em espaços heterogêneos, como, por exemplo, nas zonas rurais e urbanas.

As respostas para tais questionamentos ainda se mostram de forma incipiente, sendo o primeiro tema explorado apenas por Costa (2014), enquanto que o segundo, pelo menos a nível nacional, mostra-se inexplorado. Assim, o objetivo deste trabalho é identificar o tipo de 
comportamento existente entre a pobreza multidimensional nos espaços urbanos e rurais dos municípios brasileiros. Para tanto, foram construídos os indicadores de privação para ambos os espaços a partir da abordagem fuzzy e, em seguida, a função de distribuição conjunta destes indicadores de modo a se explorar a relação de dependência entre os mesmos através de suas respectivas distribuições marginais.

Estudos que abordam a questão da pobreza multidimensional no Brasil, nas áreas urbanas e rurais, dentre os quais Hoffmann e Kageyama (2007); Kageyama (2008) e Albuquerque e Cunha (2012) demonstram que a pobreza é mais severa nas áreas rurais. Explica-se tal fato pela ausência e/ou precariedade nessas áreas dos serviços de educação, saúde, saneamento básico, dentre outras dimensões analisadas pelos indicadores de pobreza multidimensional, o que coloca a população residente nas áreas rurais numa situação de maior vulnerabilidade, isto é, privação em relação à polução que reside em áreas urbanas.

Embora sofram com carências semelhantes, a pobreza em espaços rurais e urbanos apresentam algumas peculiaridades. No ambiente rural, fatores como o acesso à terra, água, serviços básicos de saúde e educação, formação da renda etc. são vistos como responsáveis diretos pelo estado de privação. No cenário urbano, dada a maior oferta de serviços e oportunidade de negócios, tais fatores não seria a questão central.

De fato, o que se espera, dada a natureza do problema, é que uma política seja capaz de influenciar as carências urbanas e rurais de forma homogênea. Contudo, tendo seu cerne em questões distintas, o estado de privação rural (urbano) de um município pode vir a ser menos influenciado quando ação de combate à pobreza possua elementos mais evidenciados no cenário urbano (rural). Neste sentido, seria interessante conhecer um pouco mais da relação existente entre tais cenários, para que se possa visualizar se a política de combate à pobreza contempla características que culminem numa uniformidade da ação independente do espaço.
Além desta seção introdutória, este trabalho é composto por mais quatro seções. A seguinte apresenta a discussão sobre o cenário e a análise da pobreza, tanto através da formação de indicadores, como por meio de seus aspectos em diferentes espaços. A terceira seção expõe as variáveis-bases para análise multidimensional da pobreza, bem como as metodologias de conjuntos fuzzy e cópula, que reproduziram o patamar de carência e a relação entre os mesmos, respectivamente. A quarta discutirá os resultados. Por fim, serão apresentadas as considerações finais.

\section{Pobreza: cenário e análise}

\subsection{O cenário do último censo}

Uma das características marcantes de um país continental como o Brasil é a diferença entre seus espaços, principalmente àquelas referentes aos territórios urbanos e rurais. Mesmo a nível estadual e/ou municipal a caracterização dos espaços apresenta heterogeneidades. Em 2010, de acordo com dados do censo, o contingente populacional em áreas urbanas é 5,4 vezes maior do que o rural, embora a diferença em relação à proporção de pobres seja próxima a 1,5 vez.

As diferenças entre tais localidades superam a esfera monetária e populacional. Outros indicadores, tais como analfabetismo, mortalidade e condição de moradia, também refletem o contraste existente. Primeiro, verifica-se menor proporção de analfabetos na área rural, com cerca de $30 \%$, em relação ao observado para a área urbana, com $37 \%$. Segundo, no que tange a habitação, a condição rural é mais grave, já que somente $20 \%$ das residências são construídas com material durável, contra $51 \%$ para o ambiente urbano. Por fim, relativamente, as condições de saúde, medidas pela mortalidade por cem mil vivos, são levemente superiores no espaço rural.

Tal cenário pode ser visto como consequência de uma melhor oferta de serviços e infraestrutura presente nas áreas urbanas, tornando as áreas rurais mais suscetíveis a carências, como 
destacam Hoffmann e Kageyama (2007). De fato, se há um direcionamento de recursos para um determinado espaço em detrimento de outro, é razoável supor que haja alguma forma de relação entre as necessidades de tais espaços.

\subsection{Análise da pobreza}

A pobreza pode ser definida como o estado de carência em que vivem indivíduos ou grupos populacionais, impossibilitados, devido a insuficiências de rendas ou inexistência de bens de consumo, de satisfazer suas necessidades elementares de alimentação, moradia, vestuário, saúde e educação. De acordo com Lazaroto e Raiher (2013), essa não satisfação pode ser de todos os elementos em conjunto ou em separado. Rocha (2006) define como pobre aquele indivíduo que, com sua renda familiar per capita, não consegue garantir o valor necessário para própria sobrevivência e da família. E como indigente, aquele indivíduo cuja renda familiar per capita não é suficiente nem para cobrir os gastos com a alimentação.

A escassez de renda apontada como fator determinante para a situação de pobreza ou extrema pobreza está relacionada a diversos fatores, entre eles: o desemprego, o baixo nível educacional, a baixa qualificação da mão de obra, a má distribuição da renda, a falta de competitividade da produção, como é o caso da agricultura familiar (LAZOROTO e RAIHER, 2013).

Hoffmann e Kageyama (2007), com base em dados da PNAD de 2004, realizaram a classificação da população brasileira a partir da linha de pobreza definida pela renda familiar e pela privação das condições básicas de sobrevivência, como falta de água encanada, de luz elétrica e de instalações sanitárias no domicílio. Dessa forma, ordenando o nível pobreza de acordo com a presença ou não de algumas condições elementares de sobrevivência, fundamentadas na existência de equipamentos básicos nas residências (luz elétrica, água encanada e instalações sanitárias no domicílio), concluíram que a pobreza afetava $65,1 \%$ da população residente no espaço rural e $29,2 \%$ da população residente no espaço urbano.
No que diz respeito à renda domiciliar per capita, o estudo concluiu que, em média, o rendimento rural era equivalente a apenas $42,2 \%$ do rendimento urbano.

No Brasil, segundo Kageyama (2008), a pobreza é maior na zona rural e, na região Nordeste, que concentra $85 \%$ da extrema pobreza do País, "situação em que as pessoas têm renda abaixo da linha da pobreza e vivem em domicílios que não possuem água canalizada em nenhum cômodo, nem banheiro ou sanitário e nem luz elétrica" (p. 206). A autora destaca que a região concentra grande parte da população rural, isto é, $46 \%$, e da pequena propriedade familiar do País. Também segundo ela, existem 2,8 milhões de pessoas em estado de extrema pobreza na área rural do País; já na área urbana, a parcela da população que enfrenta esse estado de pobreza é insignificante.

A redução do índice de pobreza está diretamente relacionada com a desigualdade da renda e com a renda média de um país ou região (TABOSA, IRFFI e GUIMARÃES, 2014). Para reduzir a pobreza em determinada região ou país devem ser concentrados esforços na adoção de políticas que tenham por objetivo promover o crescimento da renda média ou a redução da desigualdade da renda. Faz-se necessário discutir qual é o tipo de política que será mais eficiente no combate à pobreza, aquela que visa promover a redução da desigualdade de renda ou a que busca contribuir para elevação da renda média?

Quando se discute pobreza, a desigualdade de renda é um componente que não pode ser desconsiderado. A pobreza é um problema mundial que inclusive persiste em alguns países apesar do crescimento da riqueza material em todo o mundo. A sua extensão e gravidade podem ser verificadas por meio do número de pobres existentes em todos os países. A desigualdade e pobreza caminham lado a lado. Razão pela qual Bourguignon (2003) afirma que a redução da desigualdade de renda é um instrumento fundamental para a redução da pobreza, enquanto que, em algumas situações, o crescimento econômico pode não se constituir em um elemento tão necessário. 
Estudos realizados no Brasil por Barros e Mendonça (1998) ressaltavam a elevada taxa de desigualdade de renda no Brasil e destacavam que, de forma relativa, a redução da desigualdade é mais significante no combate à pobreza do que o crescimento econômico. Sendo assim, no caso do Brasil, recomenda-se políticas destinadas à redução da desigualdade de renda, como, por exemplo, políticas educacionais. Contudo, segundo Barreto (2005), devido a problemas de desequilíbrios regionais, como no caso da região Nordeste, o combate à pobreza deve ser realizado por meio de políticas de crescimento econômico, acompanhadas pela melhor distribuição de renda.

O estudo realizado por Tabosa, Irffi e Guimarães (2014) teve por objetivo estimar e analisar as elasticidades-renda e desigualdade da pobreza para os estados da região Nordeste do Brasil, tendo como base a suposição de que a redução da pobreza está diretamente relacionada com renda média per capita e desigualdade de renda. O período de análise foi de 1981 a 2009 e os autores utilizaram informações da PNAD como as séries de proporção de pobres $\mathrm{P}(\mathrm{a})$, proporção de indigentes, índice de Gini e renda média per capita. Os resultados alcançados sugerem que a elasticidade-renda da pobreza (tanto em relação à proporção de pobres quanto em relação à proporção de indigentes) cresceu, em valor absoluto, ao longo da década de 1980 e início da década de 1990 e, a partir de 1995, início do Plano Real, a elasticidade apresentou redução.

Com base na análise das elasticidades-desigualdade da pobreza, verificou-se que, no período depois do Plano Real, ocorreu um processo de desconcentração de renda. Mesmo assim, os níveis de desigualdade na região Nordeste continuaram elevados. Manso, Pereira e Barreto (2008) e Marinho e Soares (2003) ressaltam que em regiões com elevadas desigualdades de rendas iniciais, os aumentos de renda são repassados de forma desproporcional (ou desigual) para a população pobre da região. Observou-se também que, ao serem comparadas as elasticidades-renda e desigualdade da pobreza, tanto para a proporção de pobres quanto para a proporção de indigentes, verificou-se que os valores da elasticidade desigualdade da pobreza são maiores (em termos absolutos) do que os da elasticidade-renda. Isso significa que reduções nos níveis de desigualdade de renda são capazes de reduzir mais os níveis de pobreza do que o crescimento econômico.

Com base nos estudos mencionados, são recomendadas, principalmente, políticas que tenham por objetivo promover a redução da desigualdade para reduzir a pobreza nos estados da região Nordeste do Brasil, já que elas exercem maior impacto sobre a redução da proporção de indigentes e de pobres do que as políticas de aumento da renda média. Portanto, os gestores públicos devem direcionar maiores investimentos para educação e saúde, além de programas de acesso a crédito e microcrédito, que sejam capazes de contribuir efetivamente para redução das desigualdades de renda e promover o crescimento econômico, resultando na redução da pobreza (TABOSA, IRFFI e GUIMARÃES, 2014).

A escolha do tipo de política de combate à pobreza deve considerar as especificidades de cada região e dos espaços territoriais internos a cada uma delas; por exemplo, em áreas urbanas onde o crescimento econômico tem gerado um volume considerável de riqueza, supõe-se que a adoção de políticas que visem promover a redução da desigualdade de renda sejam mais adequadas; já em áreas rurais onde as atividades econômicas apresentam baixos níveis de produtividade e ainda não foram capazes de gerar níveis de emprego e renda suficientes para absorver parcela considerável da população local, a implementação de políticas econômicas que visem promover o crescimento econômico apresentam efeitos mais significativos na redução de pobreza, principalmente se forem adotadas conjuntamente com políticas de redução da desigualdade de renda, que permitam a população ter acesso à educação, saúde, saneamento básico, garantindo assim melhores condições de vida. 


\section{Mensuração e dependência dos indicadores de pobreza}

Para analisar a forma como a pobreza multidimensional nos espaços urbanos e rurais dos municípios brasileiros pode se relacionar será construído, primeiramente, o indicador fuzzy de pobreza multidimensional e, em seguida, as funções de distribuição empíricas destes indicadores.

A opção do índice fuzzy justifica-se sobre um dos principais pontos de críticas em estudos sobre pobreza, qual seja a escolha de uma linha de pobreza (CARVALHO, KERSTENETZKY e VECCHIO, 2007; LEMMI, 2005). Esta abordagem funciona com um método de ordenação, não caracterizando os indivíduos como pobres ou não pobres, mas sim através de um ranking indicativo de quem estaria relativamente sofrendo de menores ou maiores privações (FONSECA, 2003). No que tange a utilização da técnica de cópula, sua escolha dar-se-á entre as possíveis medidas de dependência, pelo trato com a distribuição. Diferente de outras abordagens paramétricas, que se baseiam no valor médio da distribuição, a utilização da função cópula permite captar a existência de uma relação de dependência a partir das funções de densidade marginais e, assim, incorpora em sua medida informações da distribuição como um todo.

As seguintes subseções descreveram a construção do indicador fuzzy de pobreza multidimensional para áreas urbanas e rurais dos municípios brasileiros em 2010 e a forma como a função cópula produz a função de distribuição conjunta e as marginais, da qual será extraída a medida de dependência entre os indicadores urbanos e rurais. A última subseção descreverá as variáveis de pobreza utilizadas na construção do índice fuzzy.

\section{1. Índice fuzzy de pobreza multidimensional}

Seja $X$ um conjunto e $x$ algum elemento de $X$. Logo, um subconjunto fuzzy $A$ de $X$ pode ser definido como:

$$
A=\{x, \mu A(x)\}
$$

para todo $x \in X$, em que $\mu_{A}$, a função de pertinência, é uma aplicação de $X$ em [0,1]. O valor $\mu_{A}(x)$ representa o grau de pertinência de $x$ para $A$. Caso se considere que $A$ seja um conjunto ordinal, a função de pertinência apenas assumirá valores 0 e 1 . Nesse caso:

$$
\mu_{A}(x)= \begin{cases}1, & \text { se } x \in A \\ 0, & \text { se } x \notin A\end{cases}
$$

Da mesma forma, caso $A$ caracterizar-se-á como um conjunto difuso, $\mu_{A}(x)=1$, somente se $x$ estiver contido em $\mathrm{A}$, enquanto que $\mu_{A}(x)$ $=0$ implica que $A$ não contém $x$. Por outro lado, se $x$ pertence apenas parcialmente a $A$, então $0<\mu_{A}(x)<1$. O grau de pertinência $x$ em relação à $A$ aumenta à medida que os valores de $\mu_{A}(x)$ se aproximam da unidade.

Analogamente, pode-se definir o conjunto fuzzy de pobreza. Defina $N=\{1, \ldots, n\}$ como um conjunto de elementos de uma população e $P$ como o subconjunto fuzzy dos pobres. Assim

$$
P=\{\mathrm{i}, \mu p(i)\}
$$

Com $i=(1, \ldots, \mathrm{n}\}$ e $P$ sendo o grau de pertinência de cada indivíduo $i$ ao subconjunto fuzzy de pobres. Logo, a função de pertinência poderá assumir os seguintes valores:

$\left\{\begin{array}{clc}\mu_{p}(i)=0, & \text { se } & i \text { não for pobre; } \\ \mu_{p}(i)=1, & \text { se } & i \text { for pobre; } \\ 0<\mu_{p}(i)<1, & \text { se } & i \text { possuir algum níel de pobreza. }\end{array}\right.$

Dada a natureza multidimensional da pobreza, faz-se necessário avaliar o grau de pertinência de cada indivíduo em um dado conjunto de pobres a partir de seus indicadores de privações. A questão principal é selecionar uma função de pertinência adequada para cada indicador de privação. No caso de indicadores contínuos, Cerioli e Zani (1990) apresenta a função de pertinência como segue:

$$
\mu_{\Xi j}(i)=\left\{\begin{array}{ccc}
1, & \text { se } & 0 \leq \xi_{i j} \leq \xi_{j}^{\min } \\
\frac{\xi_{j}^{\max }-\xi_{i j}}{\xi_{j}^{\max }-\xi_{j}^{\min },} & \text { se } \xi_{i j} \in\left|\xi_{j}^{\min }, \xi_{j}^{\max }\right| \\
0, & \text { se } \quad \xi_{i j}>\xi_{j}^{\max }
\end{array}\right.
$$


Em que $\xi_{j}^{\min }$ refere-se ao limiar de pobreza absoluta, abaixo do qual um determinado indivíduo pode ser considerado pobre; $\xi_{j}^{\max }$ representa o limite superior do conjunto pobreza, acima do qual o indivíduo não seria considerado pobre. Para valores presentes entre os dois limites, a função de pertinência deve ter seus valores no intervalo $[0,1]$.

Uma característica desta função é a continuidade e o formato decrescente, pelo menos nos casos em que um aumento no indicador signifique uma melhoria de bem-estar.

Definidos o conjunto fuzzy e a função de pertinência, faz necessário formalizar o processo de agregação dos $k$ indicadores de privação de forma que os mesmos sejam reduzidos a uma única dimensão. Neste sentido, a pobreza multidimensional seria considerada como um acúmulo de privações. De acordo com Martinetti (1994), uma maneira conveniente de atingir este requisito é utilizar uma média ponderada generalizada como o operador de agregação. Portanto, pode-se obter uma função de agregação expressa como segue:

$$
\begin{aligned}
& h_{\delta}\left(\mu_{\Xi i}(i), \ldots, \mu_{\Xi k}(i)\right)=\left[\sum_{j=1}^{k} \omega_{j}\left(\mu_{\Xi j}(i)^{\delta}\right)\right]^{\frac{1}{\delta}} \\
& \text { com } \omega_{j} \geq 0, j=1, \ldots, k \text { e } \sum_{j=1}^{k} \omega_{j}=1 .
\end{aligned}
$$

Em que $\delta \neq 0$ é um parâmetro referente ao tipo de média. Por exemplo, quando $\delta \rightarrow 0$, obtém-se uma média geométrica, enquanto que quando $\delta=-1, h$ corresponde a uma média harmônica. No caso em que $\delta=1, h$ reduz a média aritmética. $\mathrm{O}$ termo $\omega_{j}$ representa o peso que deve ser atribuído a cada indicador $\xi_{i}$ que comporá o processo de agregação.

Cerioli e Zani (1990) definem o grau de pertinência de cada indivíduo para o subconjunto fuzzy de pobreza tomando a média ponderada dos graus de pertinência do conjunto de privações. Formalmente,

$$
\begin{aligned}
& \mu_{p}(i)=\sum_{j=1}^{k} \omega_{j} \mu_{\Xi j}(i) \\
& \text { com } \omega_{j} \text { dado por }
\end{aligned}
$$

$$
\omega_{j}=\frac{\ln \left(1 / \bar{\mu}_{\Xi j}\right)}{\sum_{j=1}^{k} \ln \left(1 / \bar{\mu}_{\Xi_{j}}\right)}
$$

Em que $\bar{\mu}_{\Xi j}=1 / n \sum_{i=1}^{n} \bar{\mu}_{\Xi j}$ representa a proporção fuzzy de privação dos indivíduos de acordo com indicador $\xi_{i}$. Desse modo, os pesos $\omega_{j}$ são uma função inversa do nível médio de privação.

Finalmente, o Índice Fuzzy de Pobreza Multidimensional - IFP pode ser expresso como segue:

$$
I F P=1 / n \sum_{i=1}^{n} \mu_{p}(i)
$$

Por um lado, caso IFP $=0$, se e somente se $\mu_{p}(i)=0$ para cada indivíduo, não há pobreza. Por outro lado, o índice fuzzy de pobreza atinge o seu valor máximo, se e somente se $\mu_{p}(i)=1$ para cada indivíduo e, assim, observa-se extrema carência para toda a população em todos os indicadores de privação. No entanto, ambas as situações são bastante incomuns e, em geral $0<$ IFP $<1$, em que o IFP pode ser considerado uma função crescente do grau de pobreza de cada indivíduo. Portanto, uma deterioração das condições de vida de um indivíduo, coeteris paribus, resulta num aumento do IFP.

\subsection{Função cópula}

A função cópula é uma função que agrega as marginais univariadas para formar uma distribuição multivariada. Para $m$ variáveis aleatórias uniformes, $U_{1}, U_{2}, \ldots, U_{m}$, função de distribuição conjunta $C$, definida como segue

$C\left(u_{1}, u_{2}, \ldots, u_{m}, \rho\right)=$

$\operatorname{Pr}\left[U_{1} \leq u_{1}, U_{2} \leq u_{2}, \ldots, U_{m} \leq u_{m}\right]$

denomina-se função cópula.

Neste sentido, a função cópula pode ser utilizada para, através das distribuições marginais, obter-se uma distribuição conjunta. Admitindo as seguintes funções de distribuição marginais univariadas $f_{1}\left(x_{1}\right), f_{2}\left(x_{2}\right), \ldots, f_{m}\left(x_{m}\right)$, a função 


$$
C\left[f_{1}\left(x_{1}\right), f_{2}\left(x_{2}\right), \ldots, f_{m}\left(x_{m}\right)\right]=F\left[x_{1}, x_{2}, \ldots, x_{m}\right]
$$

definida pela função cópula $C$, resulta numa distribuição multivariada formada pelas funções com distribuições marginais univariadas dadas por $f_{1}\left(x_{1}\right), f_{2}\left(x_{2}\right), \ldots, f_{m}\left(x_{m}\right)$.

Esta propriedade pode ser facilmente demonstrada a seguir:

$$
\begin{aligned}
& C\left[f_{1}\left(x_{1}\right), f_{2}\left(x_{2}\right), \ldots, f_{m}\left(x_{m}\right), \rho\right]= \\
& =\operatorname{Pr}\left[U_{1} \leq f_{1}\left(x_{1}\right), U_{2} \leq f_{2}\left(x_{2}\right), \ldots, U_{m} \leq f_{m}\left(x_{m}\right)\right] \\
& C\left[f_{1}\left(x_{1}\right), f_{2}\left(x_{2}\right), \ldots, f_{m}\left(x_{m}\right), \rho\right]= \\
& =\operatorname{Pr}\left[f_{1}^{-1}\left(U_{1}\right) \leq x_{1}, f_{2}^{-1}\left(U_{2}\right) \leq x_{2}, \ldots, f_{m}^{-1}\left(U_{m}\right) \leq x_{m}\right] \\
& C\left[f_{1}\left(x_{1}\right), f_{2}\left(x_{2}\right), \ldots, f_{m}\left(x_{m}\right), \rho\right]= \\
& =\operatorname{Pr}\left[X_{1} \leq x_{1}, X_{2} \leq x_{2}, \ldots, X_{m} \leq x_{m}\right] \\
& C\left[f_{1}\left(x_{1}\right), f_{2}\left(x_{2}\right), \ldots, f_{m}\left(x_{m}\right), \rho\right]=F\left[x_{1}, x_{2}, \ldots, x_{m}\right]
\end{aligned}
$$

em que a distribuição marginal de $X_{i}$ é

$$
\begin{aligned}
& C\left[f_{1}(+\infty), f_{2}(+\infty), \ldots, f_{m}(+\infty), \rho\right]= \\
& =\operatorname{Pr}\left(X_{1} \leq+\infty, X_{2} \leq+\infty, \ldots, X_{m} \leq+\infty\right) \\
& C\left[f_{1}(+\infty), f_{2}(+\infty), \ldots, f_{m}(+\infty), \rho\right]=\operatorname{Pr}\left(X_{i} \leq x_{i}\right) \\
& C\left[f_{1}(+\infty), f_{2}(+\infty), \ldots, f_{m}(+\infty), \rho\right]=F_{i}\left(x_{i}\right)
\end{aligned}
$$

Os resultados (12) e (13) indicam que toda e qualquer função de distribuição multivariada $F$ pode ser escrita na forma de uma função de cópula. De acordo com Sklar (1973), para uma função de distribuição multivariada conjunta com funções de distribuição marginais univariadas $f_{1}\left(x_{1}\right), f_{2}\left(x_{2}\right), \ldots, f_{m}\left(x_{m}\right)$, existe uma função cópula $C\left(u_{1}, u_{2}, \ldots, u_{m}\right)$ tal que

$$
F\left[x_{1}, x_{2}, \ldots, x_{m}\right]=C\left[f_{1}\left(x_{1}\right), f_{2}\left(x_{2}\right), \ldots, f_{m}\left(x_{m}\right)\right]
$$

Sendo cada $f_{i}$ contínua, então $C$ será única. Assim, as funções de acoplamento proporcionam uma unificadora e flexível forma para estudar as distribuições multivariadas.

A função cópula apresenta as seguintes propriedades:

1. $C(v, p)=0$, para algum componente de $\mathrm{v}$ com valor nulo.

2. $C(v, p)=v_{i}, \mathrm{~V} v_{i}$ com limite superior igual a 1 , exceto o i-ésimo componente de $v$ com limite superior igual $v_{i}$.
3. Para variáveis aleatórias independentes $U$ e $V, C(u, v, \rho)=u v$.

\subsubsection{Função Cópula Gaussiana}

Buscando analisar como se dá o processo de interação entre distribuições de variáveis aleatórias, bem como determinar o patamar de dependência existente entre as mesmas, a abordagem de cópula apresenta um conjunto de funções geradoras, sendo destaque em estudos empíricos a cópula gaussiana.

Admitindo duas variáveis aleatórias, $v_{1}$ e $v_{2}$, pode-se apresentar a função geradora da Cópula Gaussiana (normal) como segue

$$
\begin{aligned}
& C\left(v_{1}, v_{2}, \rho\right)= \\
& =\int_{-\infty}^{\Phi^{-1}\left(v_{1}\right)} \int_{-\infty}^{\Phi^{-1}\left(v_{2}\right)}\left(\frac{1}{2 \pi\left(1-\rho^{2}\right)^{1 / 2}}\right) \exp \left\{\frac{-\left(s^{2}-2 \rho s t+t^{2}\right)}{2\left(1-\rho^{2}\right)}\right\} d s d t
\end{aligned}
$$

Em que $C\left(v_{1}, v_{2}, \rho\right)$ é $f d a$ da distribuição normal com o parâmetro de correlação $\rho$ restrito a $I(-1,1)$. Esta função cópula foi proposta por Lee (1983) e se caracteriza por apresentar um parâmetro de dependência que se aproxima - 1 e 1, atingindo os limites inferior e superior de Fréchet, respectivamente. A cópula normal é flexível na medida em que permite graus iguais de dependência positiva e negativa, incluindo ambos os limites de Fréchet em seu range.

A função cópula é capaz de construir a distribuição conjunta a partir $n$ funções de distribuição marginal, bem como determinar o parâmetro de dependência entre tais distribuições marginais. Contudo, a escolha do tipo de função geradora deve ser conduzida de acordo com as características das variáveis aleatórias que formam as funções de distribuição marginais, além dos sentidos que podem ser considerados plausíveis para as relações de dependência.

Neste sentido, para analisar as relações de dependência entre o IFP rural e o IFP urbano optou-se pela função cópula gaussiana, dado que os casos da família arquimediana restringem a análise de dependência ao caso positivo ou não negativo e a amostra utilizada apresentar mais de cinco mil observações. 
Tabela 1. Relação das variáveis utilizadas nas estimações

\begin{tabular}{ll}
\hline \multicolumn{1}{c}{ Variável } & \multicolumn{1}{c}{ Descrição } \\
\hline Pobreza em Renda & Percentual de pessoas pobres (P0). \\
Pobreza em Educação & Percentual de analfabetos com 15 ou mais anos. \\
Pobreza em Saúde & Mortalidade infantil por 100 mil vivos. \\
Pobreza em Habitação & Percentual de domicílios construídos com material durável. \\
\hline
\end{tabular}

Fonte: Elaboração própria.

\subsection{Descrição das variáveis}

A amostra utilizada apresenta dados sobre quatro óticas da pobreza, quais sejam renda, educação, saúde e habitação, para os ambientes rural e urbano dos 5.565 municípios do Brasil em 2010. Os dados foram retirados do censo de 2010 realizado pelo Instituto Brasileiro de Geografia e Estatística (IBGE). A Tabela 1 traz mais informações sobre a natureza dos dados utilizados.

\section{Resultados}

Baseado em informações sobre renda, educação, saúde e habitação foi construído o indicador fuzzy de pobreza multidimensional para os espaços urbanos e rurais dos municípios brasileiros. A distribuição espacial das privações encontra-se expressa nas Figuras 1 e 2. A Figura 1 relata os resultados do indicador fuzzy assumindo somente as condições de privações existentes na zona urbana dos municípios brasileiros em 2010. Indicadores mais próximos da unidade, com tom mais escuro, condizem com espaços urbanos mais carentes. Valores próximos de zero, presentes nos municípios de cor cinza, indicam níveis de privações moderados. Municipalidades grifadas de cinza claro apresentam níveis de pobrezas próximos à média.

O indicador fuzzy de pobreza multidimensional calculado para o ambiente urbano dos municípios brasileiros distribui-se de forma bastante homogênea entre estados e regiões. Apesar de exibir uma dispersão bastante expressiva em nível municipal, flutuando entre 0.01 (Valparaíso - GO) e 0.75 (Nova Belém - MG), tal indicador, em nível regional, apresenta valores semelhantes, tendo seu mínimo na região Sul e seu máximo na região
Sudeste, com 0.17 e 0.24 , respectivamente. Entre as unidades da federação observa-se o maior nível relativo de carências, 0.25 , para os estados de São Paulo e Rio de Janeiro, enquanto os estados de Roraima, Santa Catarina e Rio Grande do Sul, com índice fuzzy de 0.16, apresentaram os menores patamares de privações.

Neste sentido, apesar de a região Sudeste e, em especial, o estado de São Paulo, ser historicamente o espaço que concentra o maior volume de recursos produtivos, tal condição não garantiria uma provisão de bens capaz de ranqueá-la entre os locais urbanos com os menores indicadores de pobreza multidimensional. No outro extremo, considerada economicamente a região mais atrasada, a região Norte, que apresentou o segundo menor nível de privação, 0.19, deveria caracterizar-se entre aquelas mais carentes, fato não observado. Assim, pelo menos no que tange os espaços urbanos, uma maior concentração de atividades produtivas não necessariamente seria acompanhada por um padrão de carência moderado, contrariando a ideia de crescimento pró-pobre e expondo a desigualdade existente no Brasil como visto por Barros et al. (2007).

No que diz respeito aos elementos de composição do índice de pobreza multidimensional urbano, cabe destacar a forte influência do indicador de saúde, como um peso de 0.61 , e a baixa representatividade do indicador monetário, o qual apresentou um peso de 0.07. Ainda, observaram-se pesos de 0.13 e 0.19 para as privações em habitação e educação, respectivamente. Este resultado caracteriza o elevado nível de carências não monetárias e a contida privação monetária enfrentada no ambiente urbano dos municípios brasileiros. A precariedade na saúde 
Figura 1. IFP Urbano (Região Norte)

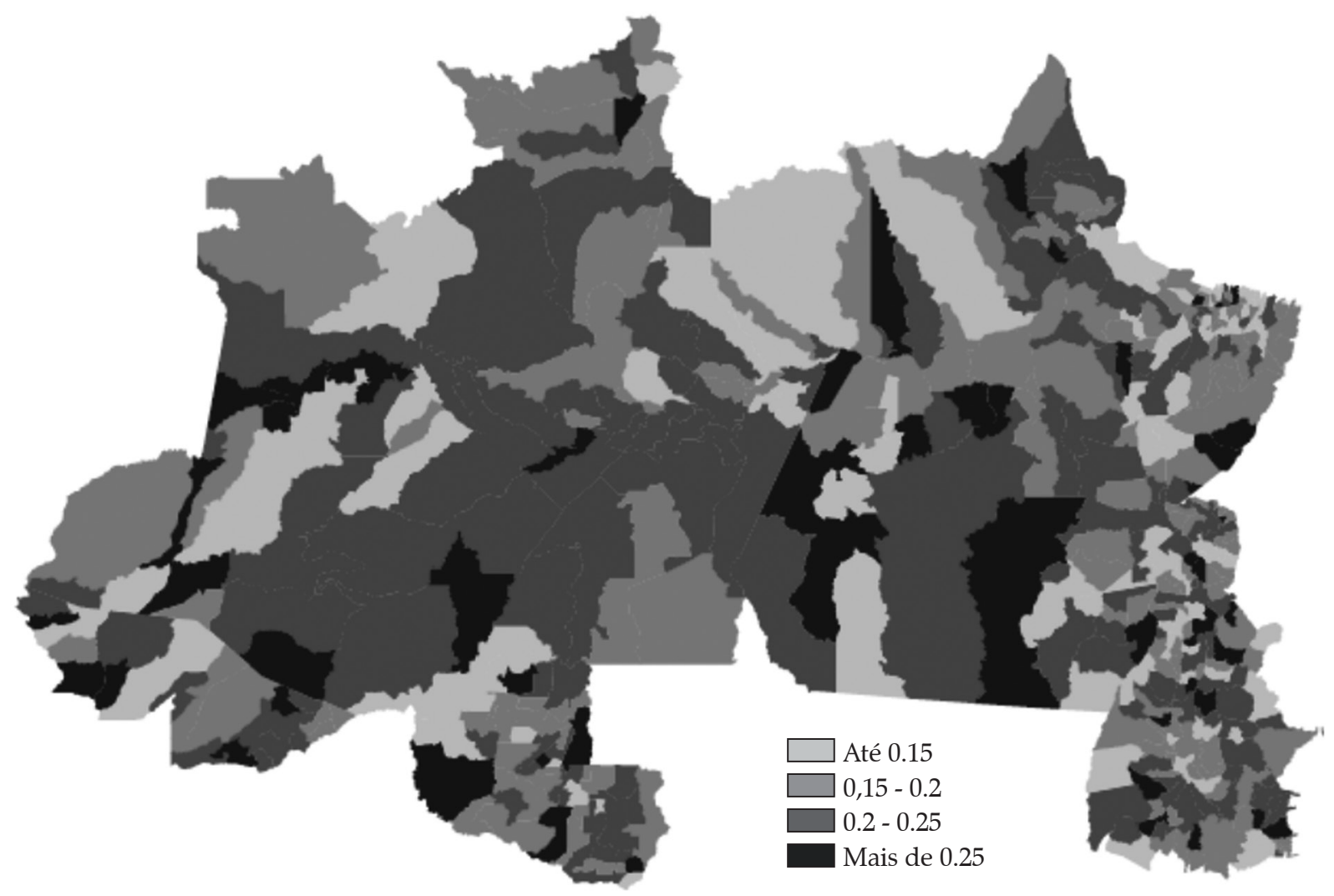

Fonte: Elaboração própria. IFP Urbano 
Figura 1. Continuação (Região Nordeste)

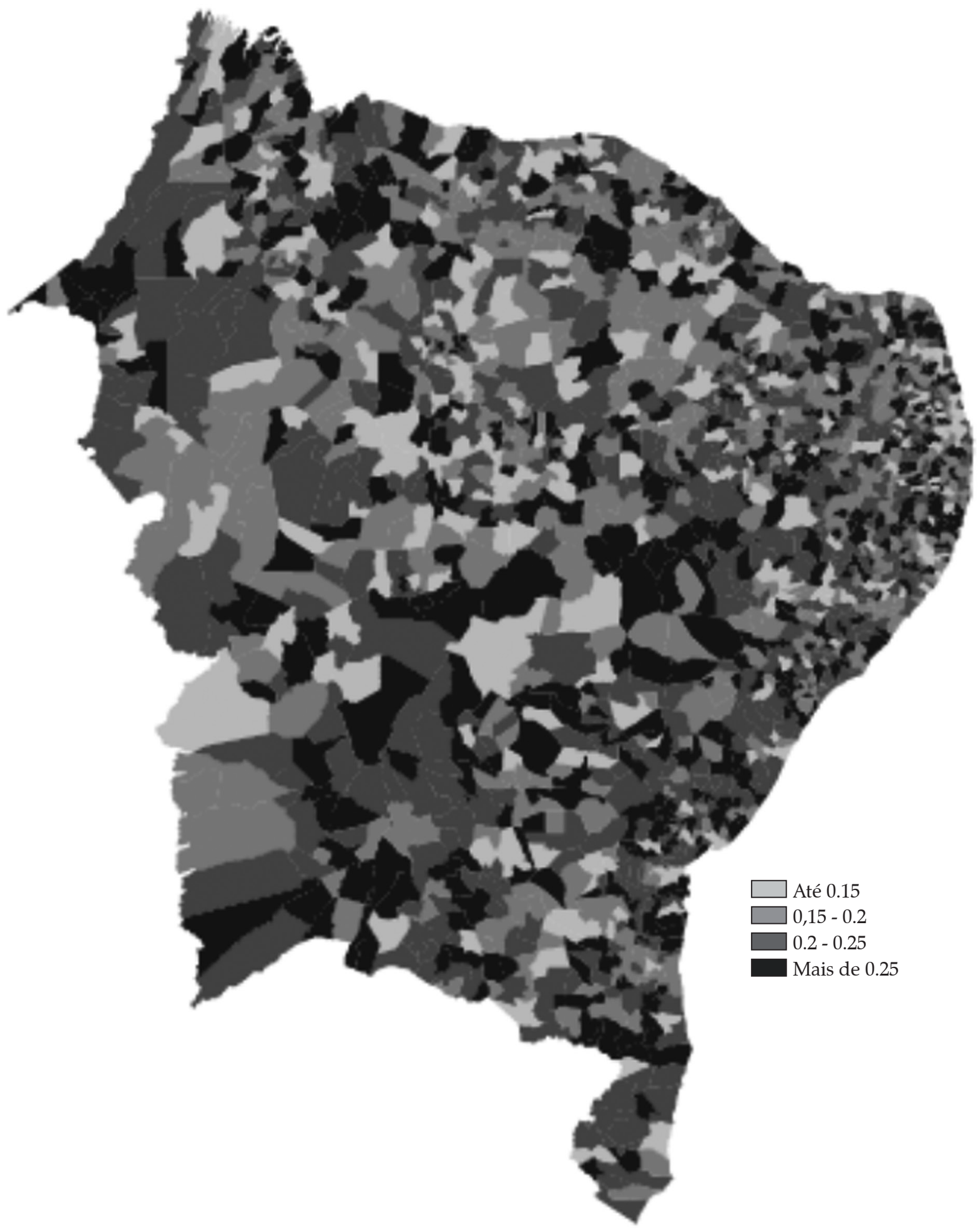

Fonte: Elaboração própria. IFP Urbano 
Figura 1. Continuação (Região Centro-Oeste)

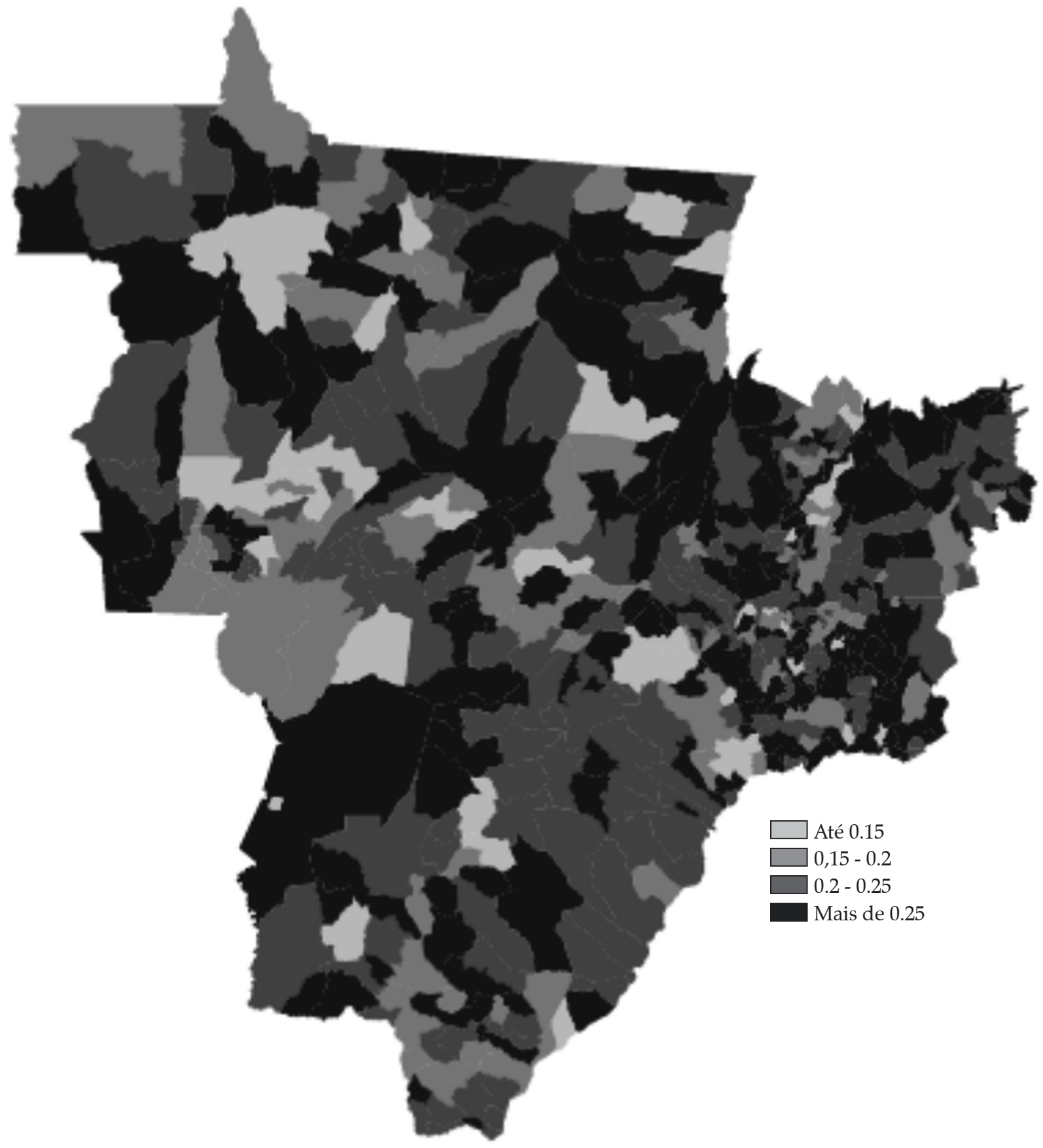

Fonte: Elaboração própria. IFP Urbano 
Figura 1. Continuação (Região Sudeste)

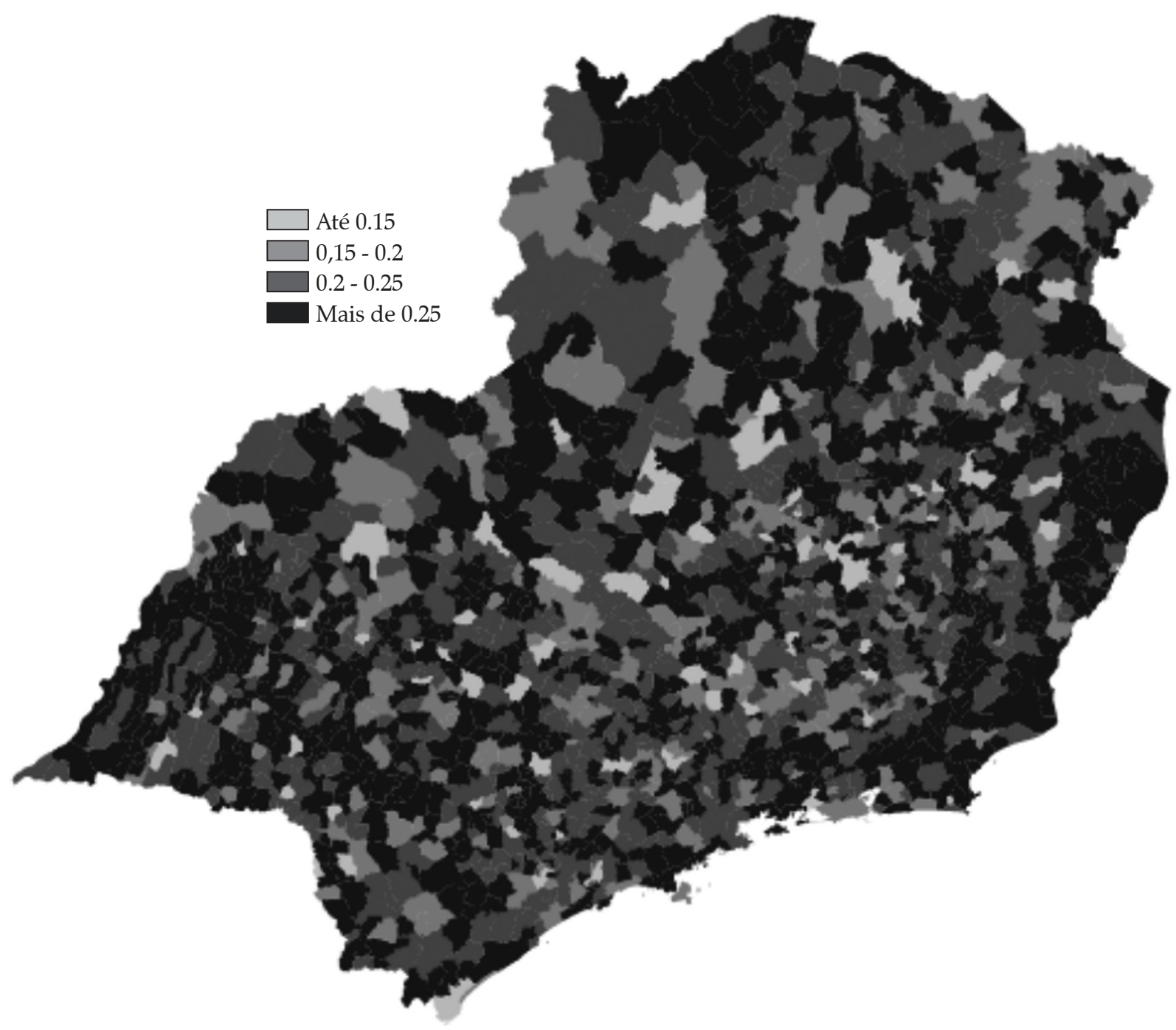

Fonte: Elaboração própria. IFP Urbano 
Figura 1. Continuação (Região Sul)

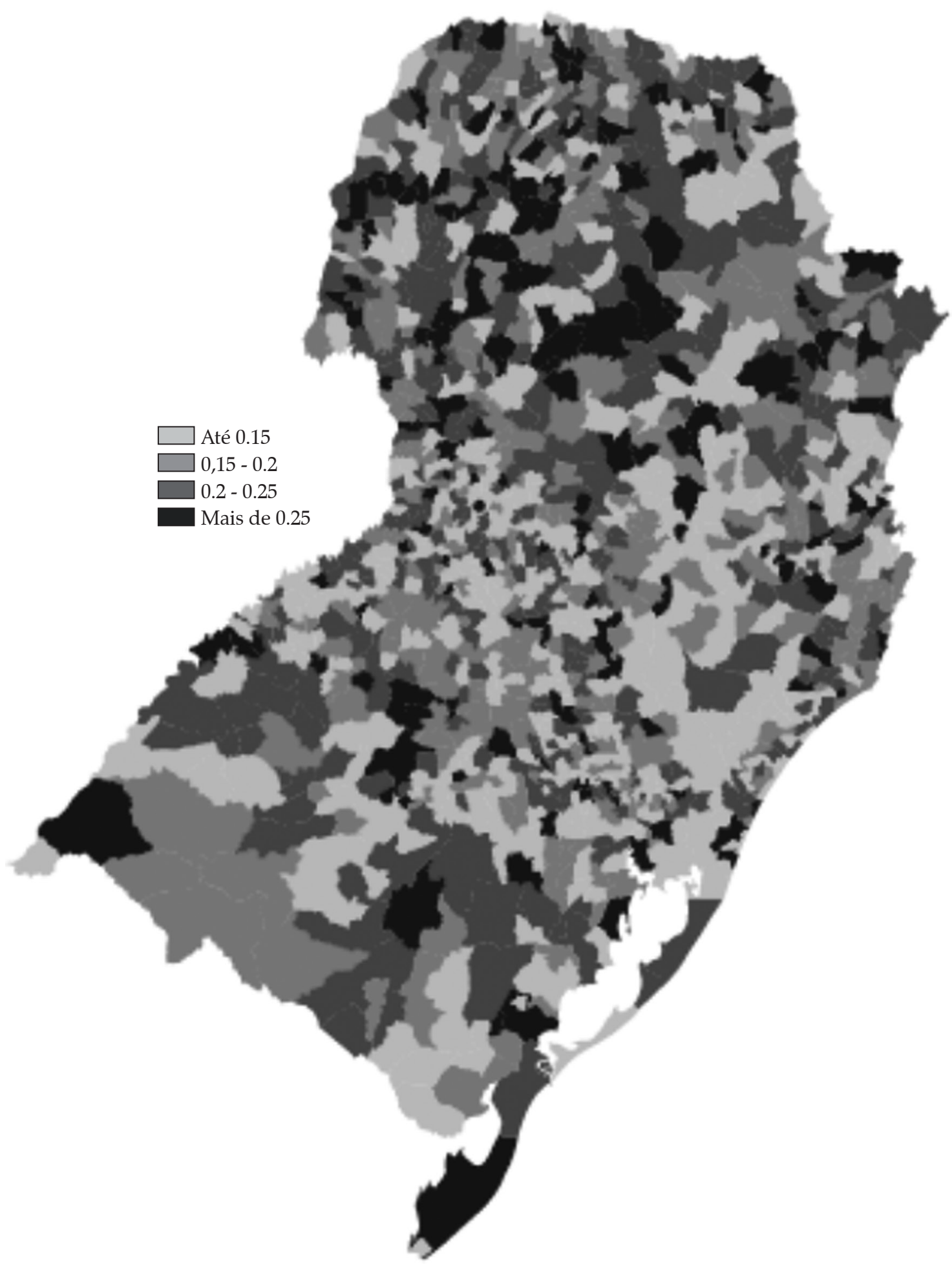

Fonte: Elaboração própria. 
Figura 2. IFP Rural (Região Norte)

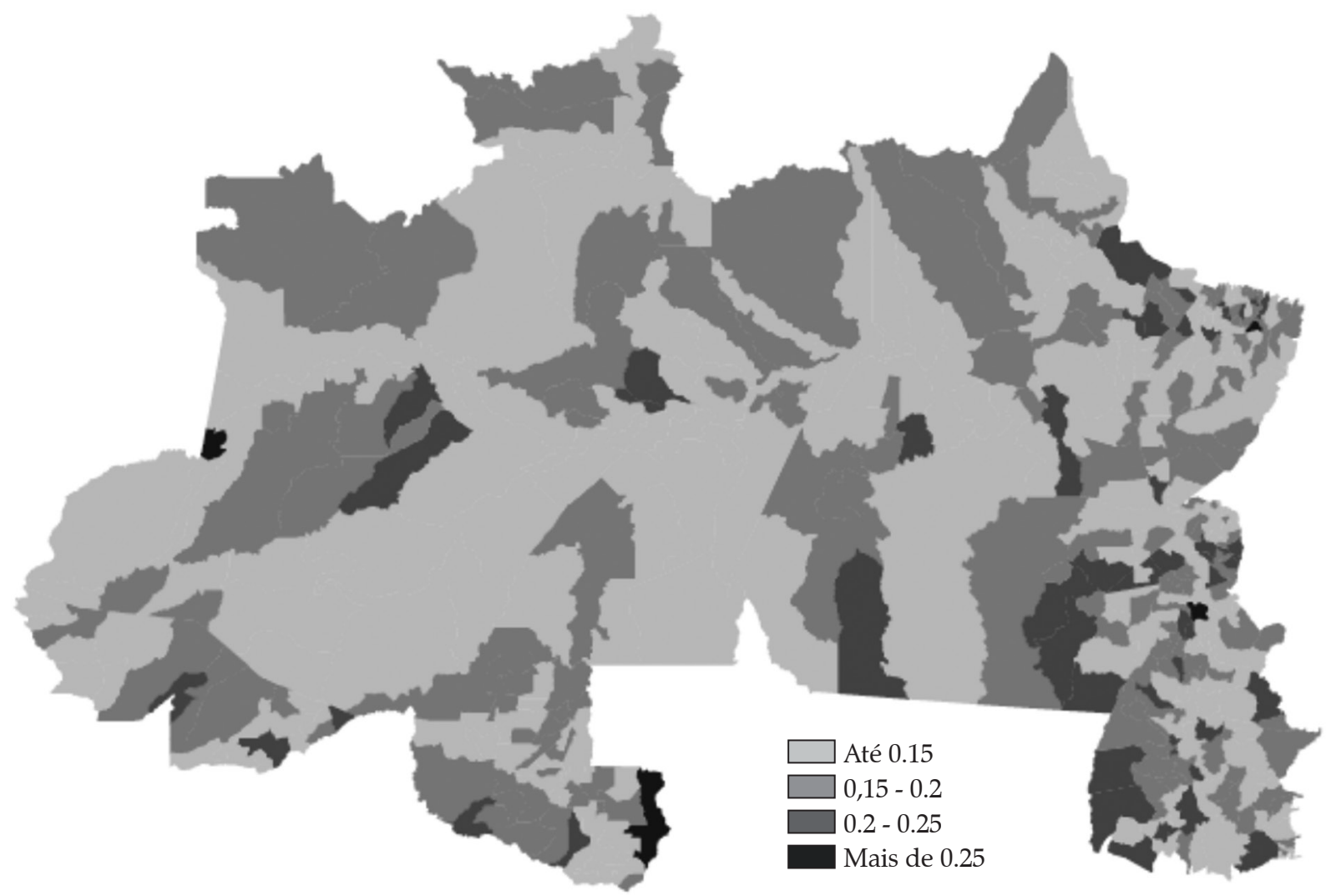

Fonte: Elaboração própria. 
Figura 2. Continuação (Região Nordeste)

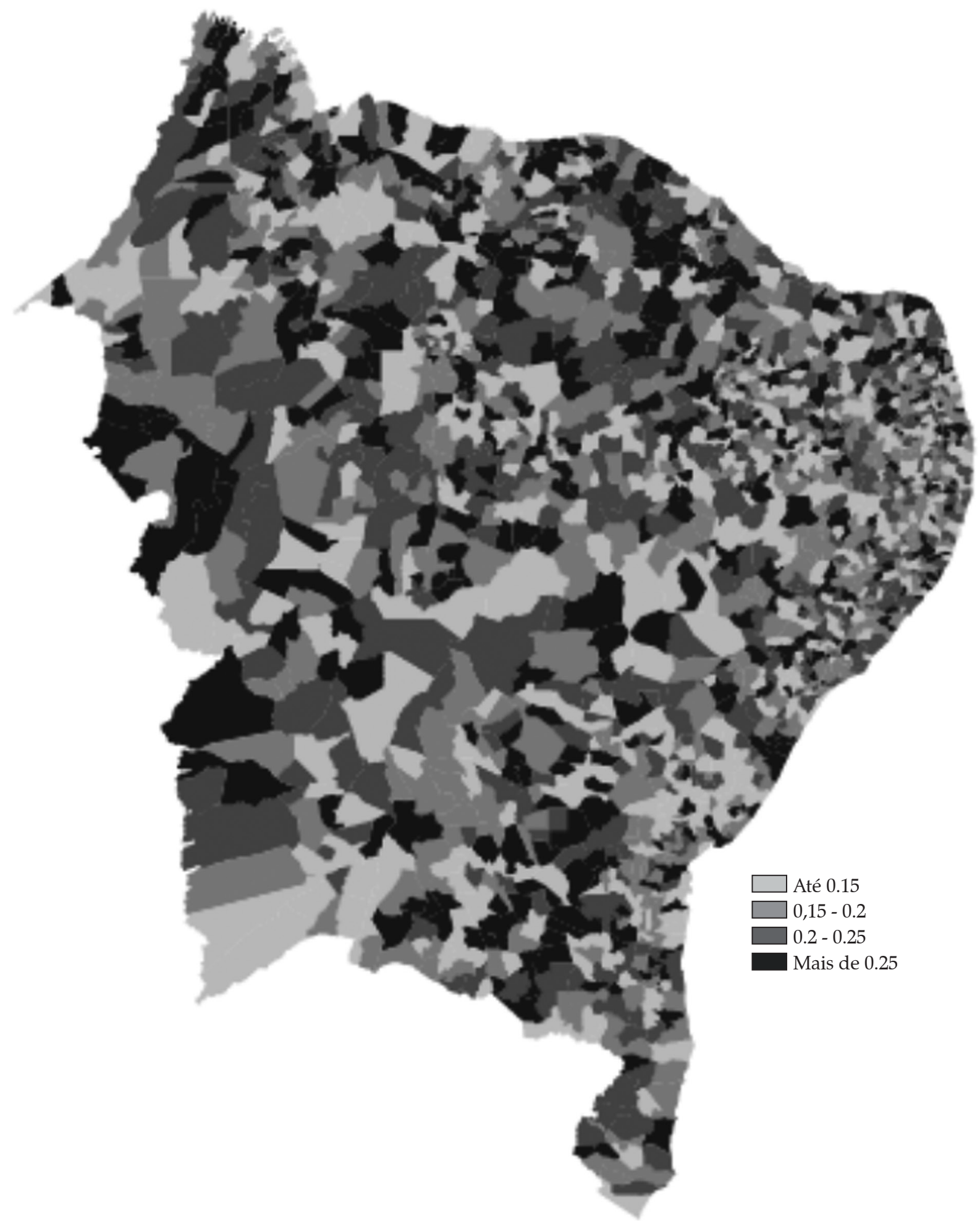

Fonte: Elaboração própria. 
Figura 2. Continuação (Região Centro-Oeste)

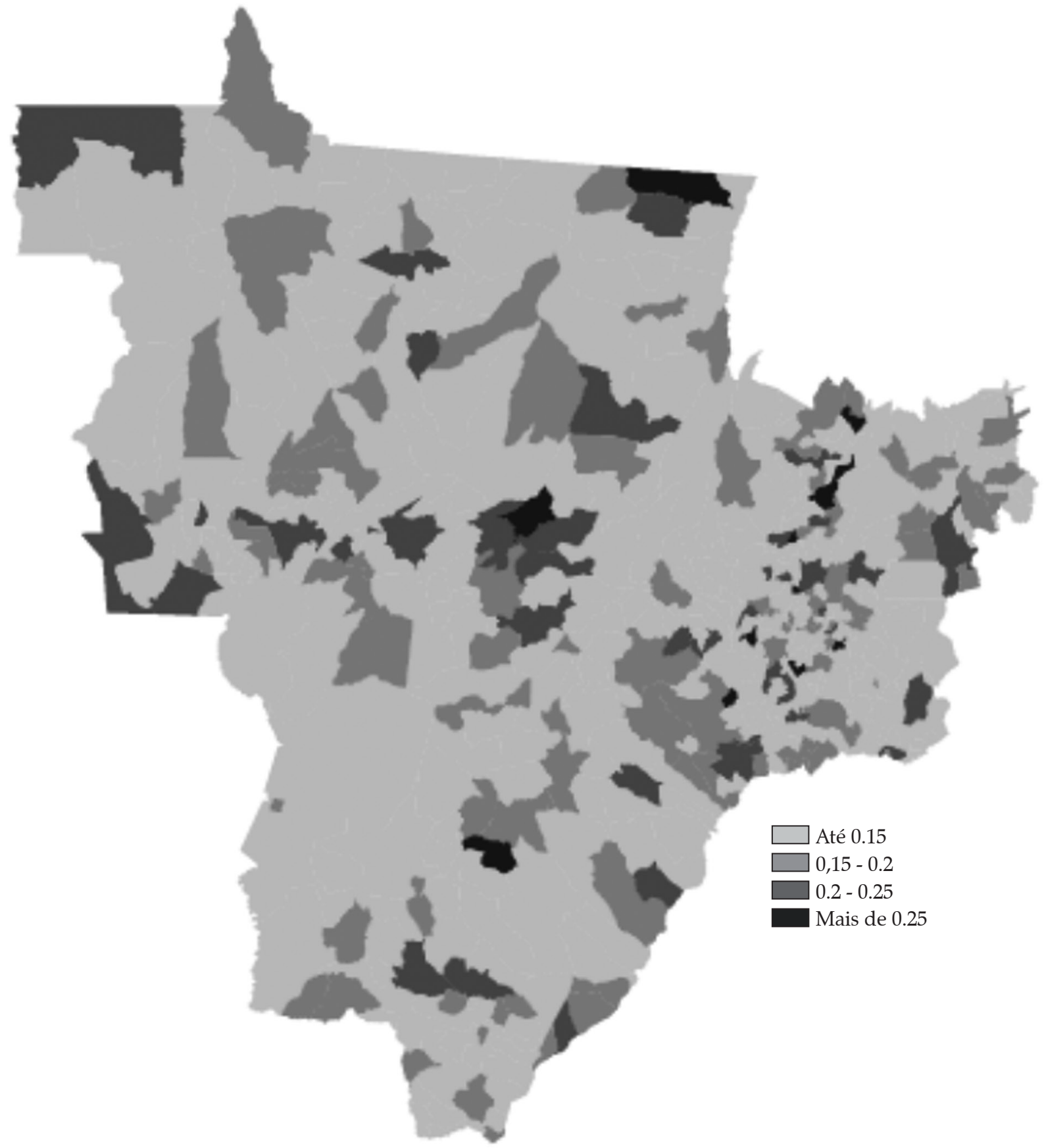

Fonte: Elaboração própria. 
Figura 2. Continuação (Região Sudeste)

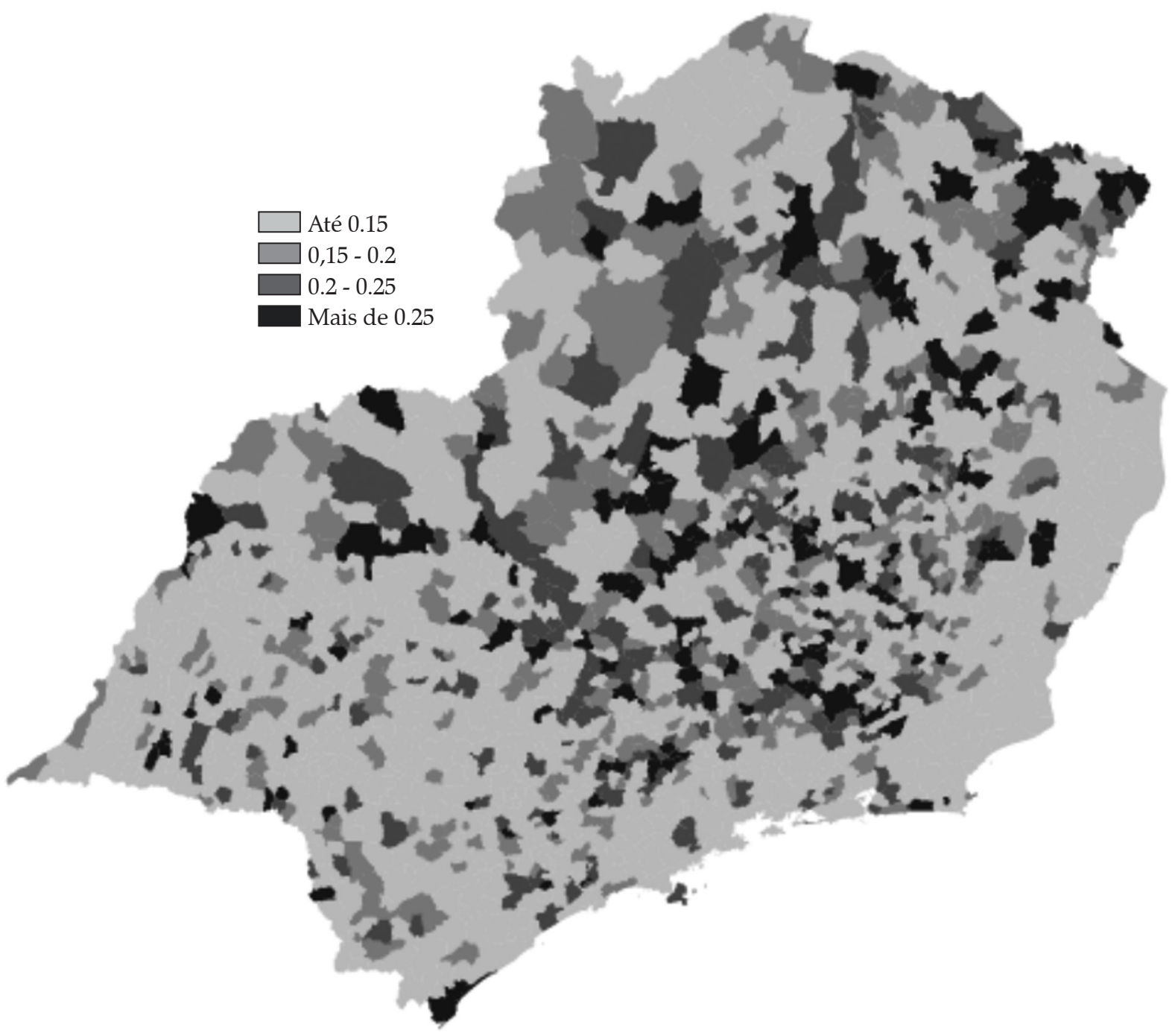

Fonte: Elaboração própria. 
Figura 2. Continuação (Região Sul)

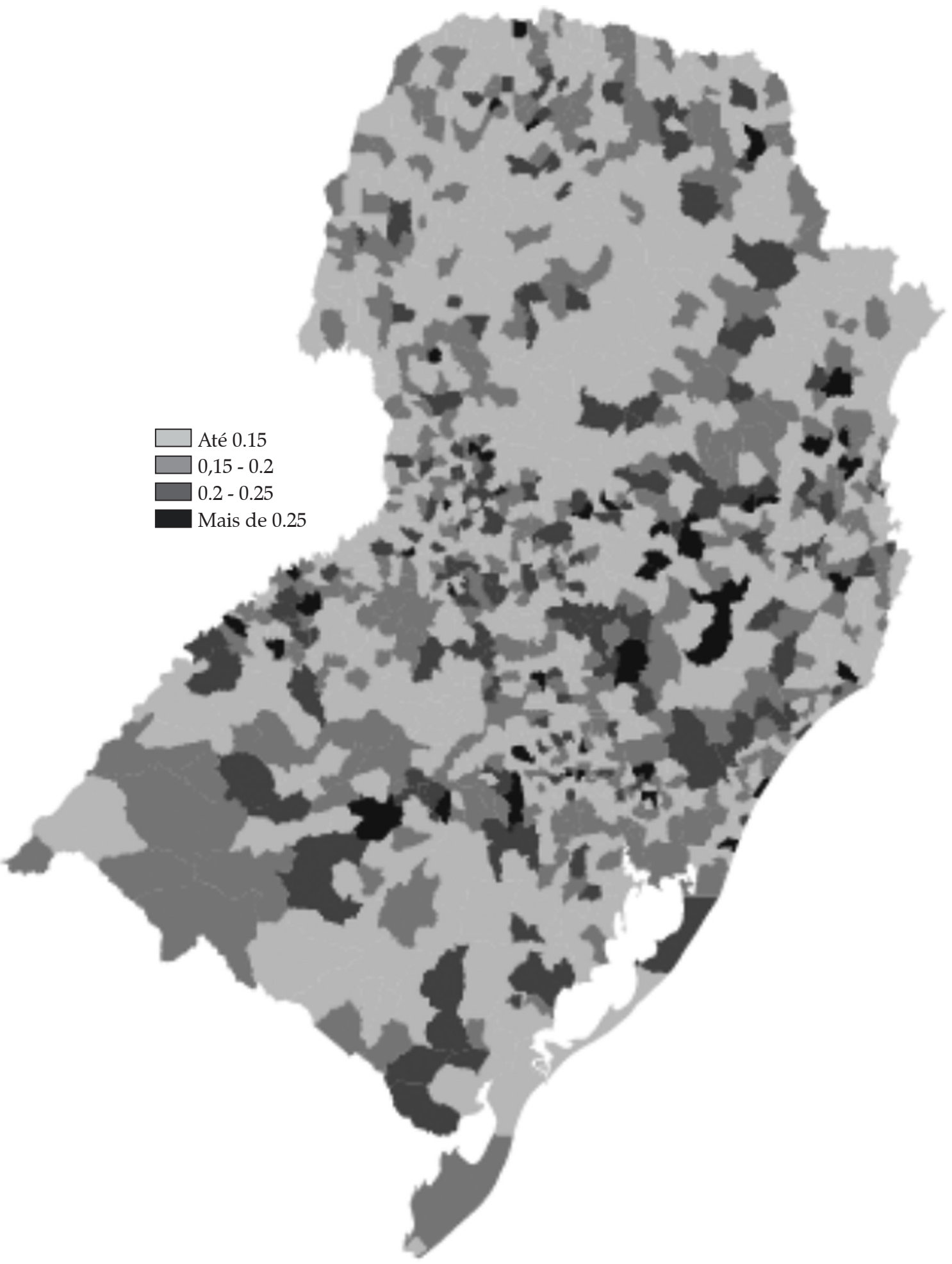

Fonte: Elaboração própria. 
pode ser vista como um dos resultados principais do então regime de políticas sociais, que prioriza a redistribuição de renda, a frequência escolar e o crédito para aquisição residencial, o que, consequentemente, amenizaria a situação de tais privações em detrimento das condições de saúde.

A Figura 2 retrata a distribuição do indicador fuzzy de pobreza multidimensional na zona rural dos municípios brasileiros em 2010. Assim como na Figura 1, as piores privações são caracterizadas por indicadores próximos à unidade, com tom mais escuro; os níveis intermediários de privação são vistos nas municipalidades grifadas em cinza; e por fim, indicadores próximos de zero, caracterizados pela cor cinza claro, referem-se aquelas localidades com menores carências.

Os resultados do índice fuzzy de pobreza multidimensional para o ambiente rural dos municípios brasileiros apresentam um patamar inferior àqueles observados para o espaço urbano. Em geral, o teto, condição extrema de privação, atinge valor de 0.65 , sendo, assim, inferior em 0.10 ao observada para o espaço urbano. A média brasileira também se mostra mais favorável. Com índice de 0.15 , a média nacional de privação indica que ambientes rurais são caracterizados por um complexo de carências mais brando.

As maiores carências a nível regional foram verificadas no Nordeste, IFP $=0.19$, enquanto que as privações rurais no Centro-Oeste, no Sudeste e no Sul mostraram-se menos severas, com 0.12 e 0.13 , para as duas últimas, respectivamente, caracterizando bem o padrão regional brasileiro. Em termos de área rural, a região Nordeste é aquela com maior volume. Portanto, seria razoável admitir que a mesma apresenta uma situação no campo mais severa em termos de privações. Em relação às unidades da federação, observa-se que grandes centros econômicos como o Distrito Federal, São Paulo e o Rio de Janeiro exibem situações de pobreza rural mais amena, enquanto que nos estados do Piauí, com IFP $=0.20$, da Paraíba, de Sergipe e da Bahia, com IFP $=0.21$, apresentaram os piores níveis de carência para as privações analisadas.

Embora a espacialização dos resultados rurais e urbanos para o índice fuzzy tenha se mostrado bastante distinta, a configuração de pesos que compõem tal indicador apresenta bastante semelhança. Assim como no caso urbano, o peso para a carência em saúde apresentou-se como a maior contribuição para IFP rural, com aproximadamente 0.60 , seguido do peso para ótica da habitação e da educação com 0.19 e 0.14 , respectivamente. Por fim, novamente, tem-se o peso para o indicador monetário como aquele menos expressivo na composição do índice fuzzy.

Uma comparação dos indicadores de pobreza permite evidenciar que as carências urbanas prevalecem sobre as rurais em praticamente todos os níveis geográficos, como também pôde ser observado por Rocha (2006) e Ravallion (2003). Embora regionalmente o IFP urbano seja sempre superior, principalmente para região Sudeste, em casos como o do estado do Piauí e em cerca de um terço dos municípios observa-se um nível de privação urbana inferior ao rural.

Descrito o perfil das privações e os resultados dos indicadores fuzzy de pobreza passa-se à análise de dependência entre tais indicadores. A medida de dependência entre o IFP rural e urbano, que permitirá o relato sobre as relações entre as pobrezas presentes nos espaços de um mesmo município, pode ser vista na Tabela 2.

Tabela 2. Dependência entre os Indicadores Fuzzy de Pobreza Multidimensional

\begin{tabular}{lcc}
\hline & IFP Urbana & IFP Rural \\
\hline IFP Urbana & 1.0000 & -0.5712 \\
IFP Rural & -0.5712 & 1.0000 \\
\hline
\end{tabular}

Fonte: Elaboração própria. 
O parâmetro de dependência obtido a partir da função cópula gaussiana deixa evidente que existe uma relação entre o indicador de pobreza multidimensional rural e, ainda, que a mesma pode ser definida de forma negativa, dado que o $\rho=-0.5712$. Neste sentido, aqueles municípios onde as privações mostram-se mais severas no espaço urbano, em média, apresentam níveis de carências mais moderadas na zona rural e vice-versa.

Para Ravallion (2003), Kageyama e Hoffman (2006) e Costa; Gasparini; Sampaio (2012), políticas de combate à pobreza promovem ganhos distintos entre os espaços urbanos e rurais devido às características produtivas destes ambientes. Como o meio rural apresenta maior dependência da produção agropecuária e a zona urbana possui uma base produtiva formada por serviços e pela indústria, dificilmente observar-se-ia uma elasticidade política-pobreza semelhante entre tais ambientes. Assim, seria natural, dadas as circunstâncias destas localidades e independente da medida socioeconômica, observar efeitos distintos sobre a pobreza. Quando as ações se destinarem a atender problemas urbanos ter-se-ia como contrapartida um efeito oneroso sobre a situação rural, e vice-versa.

\section{Considerações finais}

Visando captar o nível de pobreza multidimensional para as áreas urbanas e rurais dos municípios brasileiros e, ainda, entender como se processa a relação de dependência entre tais indicadores, foram construídos os Índices de Pobreza Multidimensional através da abordagem fuzzy e das informações sobre as privações em saúde, renda, educação e habitação, bem como as funções de densidade marginais para determinação do parâmetro de dependência.

Embora existam políticas de combate à pobreza, mínimas são aquelas que privilegiam os espaços rurais e urbanos de forma conjunta, provendo, assim, acréscimos na disparidade intramunicipal. Ainda, menores são aquelas que incorporam os efeitos das inter-relações entre as privações de modo a elevar a efetividade da medida adotada como destacado por Costa (2014).

Portanto, apesar de atingirem igualitariamente os indivíduos independentemente do ambiente, estado ou região no qual residem, os principais programas sociais de combate à pobreza não conseguem promover efeitos semelhantes sobre as carências urbanas e rurais, dado que, muito embora atinja o meio rural, sua capacidade de amenizar as privações urbanas mostra-se bastante superior.

É notória que a atuação pública em mediar a situação da pobreza não corresponde a ações baseadas em diagnósticos locais que incorporem as heterogeneidades regionais, muito menos aquelas existentes nos diversos espaços urbanos e rurais. Tal fato pode ser visto como responsável direto nas falhas de planejamento e execução de projetos de caráter socioeconômicos. Como destacam Ravallion (2003), Kageyama e Hoffman (2006) e Costa, Gasparini e Sampaio (2012), entender os diferentes cenários locais e, assim, definir ações de acordo com o perfil produtivo e/ou social das localidades e não simplesmente fornecer o mesmo remédio para pacientes distintos, seria algo plausível dentre as diversas propostas adotadas ou a serem executadas.

\section{Referências}

ALBUQUERQUE, M. R. e CUNHA, M. S. Uma análise da pobreza sob o enfoque multidimensional no Paraná. Revista de Economia, UFPR, Curitiba, v. 38, n. 3 (ano 36), p. 45-64, set./dez. 2012.

ANGELL, M. Privilege and health-what is the connection? The New England journal of medicine, v. 329, n. 2, p. 126, 1993.

BARRETO, F. A. F. D. Crescimento econômico, pobreza e desigualdade de renda: o que sabemos sobre eles? Fortaleza: Laboratório de Estudos da Pobreza/CAEN-UFC, 2005.

BARROS, R. P. e MENDONÇA, R. O impacto do crescimento econômico e de reduções no grau de desigualdade sobre a pobreza. Novos Estudos, São Paulo, v. 51, p. 107-122, 1998.

BARROS, R. P. D. et al. A importância da queda recente da desigualdade na redução da pobreza, 2007. 
BOURGUIGNON, F. e CHAKRAVARTY, S. R. The measurement of multidimensional poverty. The Journal of Economic Inequality, v. 1, n. 1, p. 25-49, 2003.

BUDDELMEYER, H. e CAI, L. Interrelated dynamics of health and poverty in Australia. IZA Discussion Papers, 2009.

CARVALHO, M., KERSTENETZKY, C. L. e VECCHIO, R. D. Uma aplicação da teoria dos conjuntos fuzzy na análise da pobreza: o caso das regiões metropolitanas do sudeste brasileiro - 2000. Anais do XXXV Encontro Nacional de Economia, ANPEC - Associação Nacional dos Centros de Pós-Graduação em Economia. Recife-PE, 2007.

CASE, A. e DEATON, A. Health and wealth among the poor: India and South Africa compared. American Economic Review, p. 229-233, 2005.

CERIOLI, A. e ZANI, S. A fuzzy approach to the measurement of poverty. In: Income and wealth distribution, inequality and poverty. Springer Berlin Heidelberg, 1990. p. 272-284.

COSTA, R. F. R. Analisando as relações entre as Multidimensões da pobreza. Encontro Nacional de Economia. Natal - RN, 2014.

., GASPARINI, C. E. e SAMPAIO, L. M. B. FPM e equidade de servicos públicos: um estudo para os municípios nordestinos. REN. Revista Econômica do Nordeste, v. 43, n. 3, p. 427-442, 2012.

FONSECA, O. Aplicação de métodos de análise espacial e da teoria de conjuntos nebulosos em estudos sobre pobreza. Dissertação (Mestrado) - Universidade Federal do Rio de Janeiro/UFRJ, 2003.

FUCHS, V. R. Reflections on the socio-economic correlates of health. Journal of Health Economics, v. 23, n. 4, p. 653-661, 2004.

GLEWWE, P. e JACOBY, H. Student achievement and schooling choice in low-income countries: Evidence from Ghana. Journal of Human Resources, p. 843-864, 1994.

HOFFMANN, R. e KAGEYAMA, A. Pobreza, insegurança alimentar e pluriatividade no Brasil. In: Congresso Da Sociedade Brasileira De Economia, Administração E Sociologia Rural, 45, 2007, Londrina. Anais... Londrina, 2007. 1 CD-ROM.

HUROWITZ, J. C. Toward a social policy for health. The New England journal of medicine, v. 329, n. 2, p. 130-133, 1993.

KAGEYMA, A. Desenvolvimento rural: conceitos e aplicações ao caso brasileiro. Porto Alegre: Editora UFRGS: Programa de Pós-Graduação em Desenvolvimento Rural, 2008.
. e HOFFMANN, R. Pobreza no Brasil: uma perspectiva multidimensional. Economia e Sociedade, Campinas, v. 15, n. 1 (26), p. 79-112, jan./jun. 2006.

LAZAROTO, J. e RAIHER, A. P. Determinantes da renda e pobreza dos agricultores do Vale do Ribeira. Revista de Política Agrícola. Brasília, ano XXII, n. 1, 2013.

LEE, L. Generalized econometric models with selectivity. Econometrica, v. 51, p. 507-512, 1983.

LEMMI, A. The fuzzy approach to multidimensional poverty: the case of Italy in the $90^{\prime}$ s. In: International Conference - The Many Dimensions of Poverty. Brasília, 2005.

MANSO, C. A., PEREIRA, D. J. S. e BARRETO, F. A. F. D. Crescimento pró-pobre: diferenças de intensidade entre rural e urbano no período 2002-2005. Revista Econômica do Nordeste, v. 39, n. 4, p. 365-385, 2008.

MARINHO, E. e SOARES, F. Impacto do crescimento econômico e da concentração de renda sobre a redução da pobreza nos estados brasileiros. In: ENCONTRO NACIONAL DA ECONOMIA, 31., 2003, Porto Seguro. Anais... Porto Seguro: ANPEC, 2003.

MARTINETTI, E. C. A new approach to evaluation of well-being and poverty by fuzzy set theory. Giornale degli economisti e annali di economia, p. 367-388, 1994.

PSACHAROPOULOS, G. e PATRINOS, H. A. Returns to investment in education: a further update. World Bank Policy Research Working Paper Series, 2002.

RAVALLION, M. The debate on globalization, poverty and inequality: why measurement matters. International Affairs, v. 79, n. 4, p. 739-753, 2003.

ROCHA, S. Pobreza e indigência no Brasil: algumas evidências empíricas com base na PNAD 2004. Nova Economia, Belo Horizonte, v. 16, n. 2, 2006.

SÁNCHEZ, M. V. e SBRANA, G. Determinants of education attainment and development goals in Yemen. Prepared for the Project Assessing Development Strategies to achieve the Millennium Development Goals in the Arab Region, UNDP-RBAS, UN-DESA and World Bank, 2009.

SANTOS, A. M. A., JACINTO, P. A. e TEJADA, C. A. O. Causalidade entre renda e saúde: uma análise através da abordagem de dados em painel com os estados do Brasil. Estudos Econômicos, São Paulo, v. 42, n. 2, p. 229261, 2012.

SCHULTZ, T. P. Accounting for public expenditures on education: an international panel study, 1995.

SEN, A. K. Poverty: an ordinal approach to measurement. Econometrica, v. 44, n. 2, p. 219-231, 1976. 
SHASHIDHAR, S., RAO, C. e HEGDE, R. Factors affecting scholastic performances of adolescents. The Indian Journal of Pediatrics, v. 76, n. 5, p. 495-499, 2009.

SKLAR, A. Random variables, joint distributions and copula. Kybernetica, v. 9, p. 449-460, 1973.

SMITH, J. P. Healthy bodies and thick wallets: the dual relation between health and economic status. The journal of economic perspectives: a journal of the American Economic Association, v. 13, n. 2, p. 144, 1999.

SOARES, R. R. The effect of longevity on schooling and fertility: evidence from the Brazilian Demographic and Health Survey. Journal of Population Economics, v. 19, n. 1, p. 71-97, 2006.
TABOSA, F. J. S., IRFFI, G. e GUIMARÃES, D. B. Elasticidades renda e desigualdade da pobreza no Nordeste de 1981 a 2009. Revista de Política Agrícola, Brasília, ano XXIII, n. 1, 2014.

TILAK, J. B. G. Post-elementary education, poverty and development in India y Role of post-basic education in alleviation of poverty and development. Centre of African Studies, University of Edinburgh, 2005.

WILSON, K. The determinants of educational attainment: modeling and estimating the human capital model and education production functions. Southern Economic Journal, p. 518-551, 2001. 
